\title{
Implications of thematic reuse in Haydn's sonata forms
}

\author{
Jan Miyake \\ Oberlin College \& Conservatory, Oberlin, OH, USA \\ jan.miyake@oberlin.edu \\ Published 16 December 2021; https://doi.org/10.18061/FDMC.2021.0010 \\ Author video presentation and/or other conference material: https://doi.org/10.17605/OSF.IO/Z7BXU
}

\begin{abstract}
Haydn's approach to form is underserved by current theories as discussed by Burstein (2016), Duncan (2011), Fillion (2012), Korstvedt (2013), Ludwig (2012), Neuwirth (2011, 2013), and Riley (2015). Comparing Haydn to composers a generation younger (Mozart and Beethoven) instead of with his contemporaries (such as Dittersdorf and Vanhal) distorts what is, and what is not, idiosyncratic about his compositional form. His inclination to reuse the opening theme later in the movement can impact the melody of his $\mathrm{S}$ theme, the path to and through his recapitulations, and the construction of his phrase's middles (Miyake, 2011). This compositional feature, however, often leads to forms that do not fit neatly into theories of Classical Era form forwarded by Caplin (2001) and Hepokoski and Darcy (2006). The concept of thematic saturation provides a window into investigating how Haydn reuses themes. The quantity and density of thematic saturation measure different aspects of thematic reuse and further our understanding of Haydn's approach to form. This project is part of a larger project that investigates whether patterns of thematic returns are independent of traditional formal designations (sonata form, sonata rondo, ABACA).
\end{abstract}

KEYWORDS: sonata form, thematic saturation, monothematicism, Haydn

\section{Introduction}

Monothematicism is connected with Haydn by almost every writer on the topic (Tilmouth, 2001). Similarly, overviews of Haydn's instrumental works invariably discuss Haydn's use of monothematicism. Monothematic sonata forms, however, account for only a fraction of the many ways Haydn recycles his opening theme. Investigating thematic reuse across a movement allows an analyst to move beyond the conception of form as a static container to be filled, to the conception of form as a process that unfolds in time. Thematic reuse often impacts the paths that Haydn's sonata forms travel, and it can require Procrustean efforts to fit these journeys into a mold made for Beethoven or Mozart. Burstein (2016), Duncan (2011), Fillion (2012), Korstvedt (2013), Ludwig (2012), Neuwirth (2011,
2013), and Riley (2015) all document how Haydn's music is underserved by current theories of form.

The term monothematic specifically refers to a sonata form exposition in which the secondary theme (S) parallels the primary theme (P), but in the new key. Rosen (1998) and Miyake (2011) problematize the term "monothematic" because (1) the P-based S typically diverges from $\mathrm{P}$ to create a contrasting theme and (2) monothematic expositions usually include a non Pbased C-theme. While Haydn frequently uses P-based S themes, a related trademark of his style is his proclivity for reusing his $\mathrm{P}$ theme to initiate a wide range of formal areas. These formal areas include sections of a sonata form (e.g., the development or coda), subsections of a sonata-form section (e.g., sequences in the development or the transition of an exposition), and beginnings within phrases (e.g., the latter phrase of a period, a or module of a multi-modular theme).

Scholars have noted Haydn's thematic reuse, but few engage deeply with it. Hepokoski and Darcy's Sonata Theory (2006) develops language for describing techniques of thematic return. Two examples of this language are "The P-based C" (p. 184) and "The Onset of the Development; P-Material as the Norm" (p. 207). Caplin (2001) also accounts for thematic reuse in his Formenlehre. Two examples, chosen to parallel the Hepokoski and Darcy examples, are subsections on "Main-theme material" when discussing beginning the transition (p. 117) and on "Main theme's basic idea" in a description of ways to begin the pre-core of a development (p. 151). Neither of these theories are designed to look at the impact that thematic reuse has across an entire form. Unlike Caplin, Hepokoski \& Darcy, Haimo (1995) wrestles with the impact that thematic reuse can have on a movement. His unity, redundancy, and variation principles work together to address the impact of thematic saturation on Haydn's compositions. This current work has more in common with Haimo than Caplin, Hepokoski and Darcy because it forwards the concept of thematic saturation to deepen our understanding of how thematic reuse unfolds across a sonata form. 


\section{Method}

\section{Measuring thematic saturation}

Investigating thematic reuse starts with building a corpus of thematic returns. I analyzed nearly 200 movements to list every instance of a thematic return. All movements are last movements, and their attribution to Haydn has not been disproven. Compared with first movements, final movements are less bound by convention and can be organized in a variety of ways, not just as a sonata form. Thematic returns have a formal function of beginning and reuse at least the basic idea of the original theme. Returns can initiate passages at any level of form (e.g., development, consequent phrase, sequence, or S-theme). Thematic returns are a subset of motivic returns. The former must have a formal function of a beginning while the latter can have any formal function. The analyses of the final movements of Haydn's symphonies, keyboard trios, and keyboard sonatas generated 1684 thematic returns from 189 last movements, of which 781 thematic returns come from 99 last movements organized as a sonata form. [1]

The data measure thematic saturation in two ways. Quantity is the percentage of the bars, including those constituting the first theme, that participate in thematic saturation. Density is a count of the number of instances of thematic saturation normalized by dividing the count by the total number of heard measures. Quantity accounts for the length of the return while density does not.

\section{Thematic Plans of Expositions \& Monothematicism}

The thematic plan of an exposition details how thematic reuse impacts the zones of an exposition. By definition, all P-themes are launched by the first theme. Later zones-TR, S, and $\mathrm{C}$ - can also be initiated by the $\mathrm{P}$ theme. There are eight possible plans (Table 1), of which half would be labeled monothematic.

Table 1: Possible thematic plans of a sonata form exposition. $y / n$ indicates whether or not the main theme initiates that zone of the exposition.

\begin{tabular}{|c|c|c|c|c|c|c|c|c|}
\hline \multicolumn{4}{|c|}{ Not monothematic } & \multicolumn{5}{|c|}{ Monothematic } \\
\hline $\mathrm{P}$ & $\mathrm{TR}$ & $\mathrm{S}$ & $\mathrm{C}$ & $\mathrm{P}$ & $\mathrm{TR}$ & $\mathrm{S}$ & $\mathrm{C}$ \\
\hline $\mathrm{y}$ & $\mathrm{n}$ & $\mathrm{n}$ & $\mathrm{n}$ \\
$\mathrm{y}$ & $\mathrm{y}$ & $\mathrm{n}$ & $\mathrm{n}$ \\
$\mathrm{y}$ & $\mathrm{n}$ & $\mathrm{n}$ & $\mathrm{y}$ \\
$\mathrm{y}$ & $\mathrm{y}$ & $\mathrm{n}$ & $\mathrm{y}$ & $\mathrm{n}$ & $\mathrm{y}$ & $\mathrm{n}$ \\
\hline $\mathrm{y}$ & $\mathrm{y}$ & $\mathrm{y}$ & $\mathrm{y}$ & $\mathrm{y}$ & $\mathrm{n}$ \\
\hline & $\mathrm{y}$ & $\mathrm{n}$ & $\mathrm{y}$ & $\mathrm{y}$ \\
\hline & $\mathrm{y}$ & $\mathrm{y}$ & $\mathrm{y}$ & $\mathrm{y}$ \\
\hline
\end{tabular}

Table 2 organizes the possible thematic plans by how many times the main theme initiates a thematic area, highlighting the monothematic plans with a blue font, and providing a count of Haydn's use of each plan in the corpus. While monothematic expositions represent one way an exposition can be thematically saturated, the term omits other equally saturated thematic plans.

Table 2: Possible thematic plans presented from least saturated by the opening theme to most saturated. Monothematic expositions are in blue.

\begin{tabular}{|c|c|c|c|c|c|}
\hline $\mathbf{P}$ & TR & $\mathbf{S}$ & $\mathbf{C}$ & $\begin{array}{l}\text { \# of thematic } \\
\text { areas initiated by } \\
\text { the main theme }\end{array}$ & $\begin{array}{c}\% \text { of } \\
\text { corpus } \\
(\text { size }=99) \\
\end{array}$ \\
\hline $\mathrm{y}$ & $\mathrm{n}$ & $\mathrm{n}$ & $\mathrm{n}$ & 1 & 41 \\
\hline $\mathrm{y}$ & $\mathrm{y}$ & $\mathrm{n}$ & $\mathrm{n}$ & \multirow{3}{*}{2} & 25 \\
\hline$y$ & $n$ & $y$ & $n$ & & 13 \\
\hline $\mathrm{y}$ & $\mathrm{n}$ & $\mathrm{n}$ & $\mathrm{y}$ & & 2 \\
\hline$y$ & $y$ & $y$ & $n$ & \multirow{3}{*}{3} & 10 \\
\hline $\mathrm{y}$ & $\mathrm{y}$ & $\mathrm{n}$ & $y$ & & 3 \\
\hline$y$ & $n$ & $y$ & $y$ & & 4 \\
\hline$y$ & $y$ & $y$ & $y$ & 4 & 1 \\
\hline
\end{tabular}

Impacts of thematic reuse are investigated by calculating the average quantity and density for each possible exposition plan as well as by the presence of each P-based zone of the exposition.

\section{Results}

Table 3 reports the corpus's average quantity and density of thematic saturation for each type of P-based theme. As the exposition unfolds, the presence of a Pbased theme generally increases the quantity and density of thematic saturation.

Table 3: Average quantity and density of thematic saturation given the existence of a P-based theme

\begin{tabular}{|c|c|c|c|}
\hline $\begin{array}{c}\text { P-based } \\
\text { thematic zone }\end{array}$ & Quantity & Density & $\begin{array}{c}\text { Count in corpus } \\
\text { (size = 99) }\end{array}$ \\
\hline only P & $22 \%$ & .034 & 41 \\
\hline Includes TR & $27 \%$ & .061 & 39 \\
\hline Includes S & $26 \%$ & .069 & 28 \\
\hline Includes C & $29 \%$ & .079 & 10 \\
\hline All sonata forms & $24 \%$ & .051 & 99 \\
\hline
\end{tabular}

Table 3 double or triple counts several expositions because $19 \%$ of the corpus have three or four expositional zones initiated by P. Tables 4 and 5 break the quantity and density of thematic saturation down by 
thematic plan while figures 1 and 2 visually represent the data.

Table 4: Possible thematic plans presented from least saturated by the opening theme to most saturated. Monothematic expositions are in blue.

\begin{tabular}{|c|c|c|c|c|c|}
\hline $\mathbf{P}$ & TR & $\mathbf{S}$ & $\mathbf{C}$ & \multicolumn{2}{|c|}{$\begin{array}{r}\text { Average Quantity of Thematic } \\
\text { Saturation }\end{array}$} \\
\hline $\mathrm{y}$ & $\mathrm{n}$ & $\mathrm{n}$ & $\mathrm{n}$ & $22 \%$ & $22 \%$ \\
\hline $\mathrm{y}$ & $\mathrm{y}$ & $\mathrm{n}$ & $\mathrm{n}$ & $25 \%$ & \multirow{2}{*}{$24 \%$} \\
\hline$y$ & $n$ & $y$ & $n$ & $22 \%$ & \\
\hline $\mathrm{y}$ & $\mathrm{n}$ & $\mathrm{n}$ & $\mathrm{y}$ & $30 \%$ & \multirow{2}{*}{$30 \%$} \\
\hline$y$ & $y$ & $y$ & $n$ & $29 \%$ & \multirow{2}{*}{$50 \%$} \\
\hline $\mathrm{y}$ & $\mathrm{y}$ & $\mathrm{n}$ & $\mathrm{y}$ & $36 \%$ & \\
\hline$y$ & $n$ & $y$ & $y$ & $27 \%$ & $50 \%$ \\
\hline$y$ & $y$ & $y$ & $y$ & $50 \%$ & \\
\hline
\end{tabular}

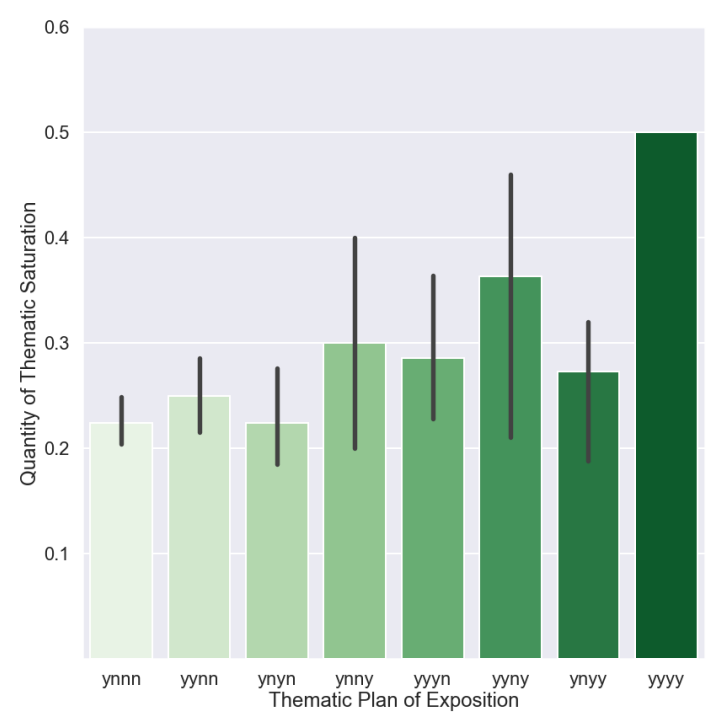

Figure 1: Quantity of Thematic Saturation means for each exposition plan

Table 5: Possible thematic plans presented from least saturated by the opening theme to most saturated. Monothematic expositions are in blue.

\begin{tabular}{|c|c|c|c|c|c|}
\hline $\mathbf{P}$ & $\mathbf{T R}$ & $\mathbf{S}$ & $\mathbf{C}$ & \multicolumn{2}{|c|}{$\begin{array}{c}\text { Average Density of Thematic } \\
\text { Saturation }\end{array}$} \\
\hline $\mathrm{y}$ & $\mathrm{n}$ & $\mathrm{n}$ & $\mathrm{n}$ & .034 & .034 \\
\hline $\mathrm{y}$ & $\mathrm{y}$ & $\mathrm{n}$ & $\mathrm{n}$ & .051 & \multirow{2}{*}{.056} \\
\hline$y$ & $n$ & $y$ & $n$ & .058 & \\
\hline $\mathrm{y}$ & $\mathrm{n}$ & $\mathrm{n}$ & $\mathrm{y}$ & .087 & \\
\hline$y$ & $y$ & $y$ & $n$ & .068 & \multirow{2}{*}{.075} \\
\hline $\mathrm{y}$ & $\mathrm{y}$ & $\mathrm{n}$ & $\mathrm{y}$ & .091 & \multirow{2}{*}{.075} \\
\hline$y$ & $n$ & $y$ & $y$ & .082 & .144 \\
\hline$y$ & $y$ & $y$ & $y$ & .144 & \\
\hline
\end{tabular}

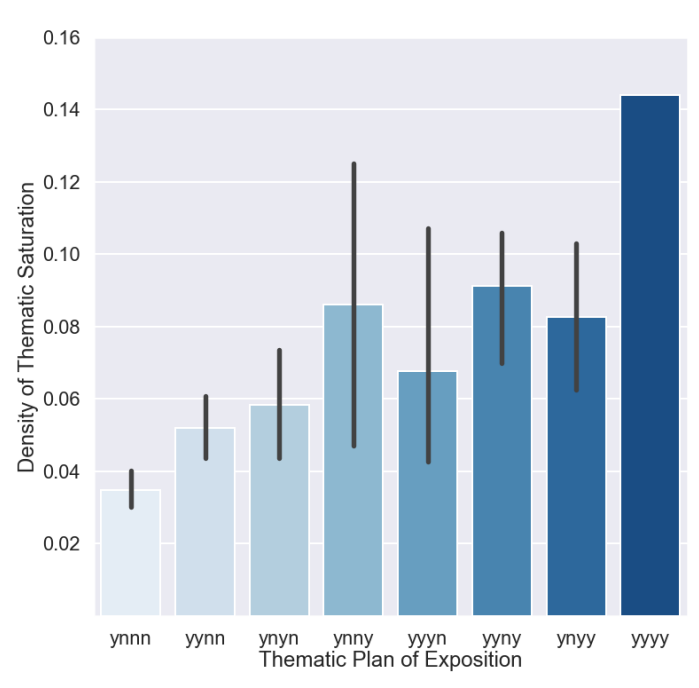

Figure 2: Density of Thematic Saturation means for each exposition plan

\section{Discussion}

In this corpus, Haydn's penchant for thematic reuse within the exposition is clear: Table 2 shows that approximately $60 \%$ of his expositions launch at least one future zone with the P-theme. While Haydn was equally likely to initiate one future exposition section with $\mathrm{P}(40 \%$ of corpus) as he was to initiate no future exposition sections ( $41 \%$ of corpus), the 19\% of expositions with higher degrees of thematic saturation skew the balance towards reusing the P-theme later in the exposition. Even though we believe Haydn writes more monothematic expositions than Beethoven and Mozart, we do not yet have the data to compare these composers' overall thematic reuse in the exposition. Clearly P-based TRs and P-based Cs are common enough to be defaults in Hepokoski and Darcy's typology of exposition possibilities (Hepokoski and Darcy 2006, pp. 101 and 184).

Table 3 shows that the presence of future exposition zones initiated by the P-theme impacts the movement's quantity and density of thematic saturation. The impact on quantity is less pronounced than the impact on density. Since density measures the number of returns and quantity the number of measures in the return, it is clear that Haydn does not recycle the complete theme. Additionally, the later the thematic recycling occurs in the exposition, the larger the impact on the number of future returns; P-based $\mathrm{C}$ sections lead to more 
thematically saturated movements than P-based TR sections.

When considering how intensely a piece is saturated by its main theme, it is tempting to connect thematic saturation with monothematicism. The two concepts, however, refer to distinctly different phenomenon. Monothematicism is defined solely by the contents of an exposition, focusing on comparing the opening bars of $\mathrm{S}$ with the opening bars of $\mathrm{P}$. It ignores other thematic events in the exposition and in the rest of the movement (development, recapitulation, and coda). Thematic saturation, on the other hand, examines the reuse of P's opening throughout the entire movement. It has the potential to capture thematic reuse in other exposition sections, the development, and in Haydn's varied approaches to the recapitulation.

Tables 4 and 5 demonstrate that monothematic expositions from this corpus lead to less saturated movements than non-monothematic exposition with thematic reuse (P-based TR and/or P-based C). In thematic plans with two or three exposition zones initiated by the P-theme, those including a P-based S theme, in a blue font, were the least saturated of the group, with one exception: the density of thematic satuation of the "ynyn" exposition plan. In fact, the existence of a P-based $\mathrm{C}$ theme leads to the highest degrees of density and quantity of thematic saturation. This observation about P-based $\mathrm{C}$ themes is also supported by Table 3 .

The data additionally capture Haydn's penchant for launching a section with $\mathrm{P}$ material and then proceeding to develop it in new ways (Figure 3 ). In Table 4, the average quantity of thematic saturation was the same for the least saturated expositional plan ("ynnn," no future P-based themes) and the least saturated monothematic plan ("ynyn," only a S-based P theme): $22 \%$. But, when comparing these two plans' density of thematic saturation in Table 5, drastically different results emerge: .034 compared with .058 . This divergence in similarity shows that, for these two plans, Haydn created equal amounts of content (quantity) based on reusing $\mathrm{P}$ 's beginning as a future beginning but did so far more frequently (density) in the monothematic plan. In other words, in the more thematically saturated work, Haydn does not bring back the entire P-theme. Rather, he both uses that opening more frequently to launch future areas and then recycles less of the theme before developing it in new ways. This approach to thematic reuse is noted in any significant discussion of Haydn's monothematicism, but the pairing of these two expositional plans quantifies and captures the impact that an exposition's degree of thematic saturation has on the entire movement.
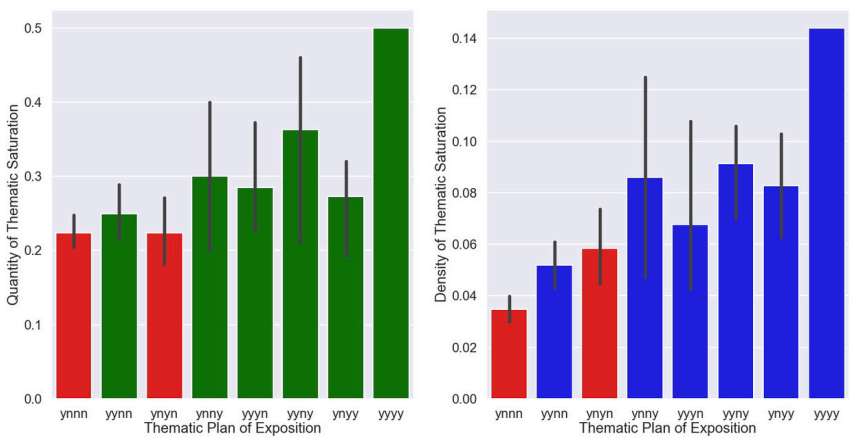

Figure 3: Highlighting how two plans with equal quantity of thematic saturation have unequal density of thematic saturation.

\section{Conclusion}

Thematic reuse is an aspect of Haydn's style that is important and undertheorized. In a sonata form, the thematic saturation of the expositional plan impacts how the rest of the movement unfolds. Monothematicism, a trademark of Haydn's style, and thematic saturation connect in counterintuitive ways. The presence of a Pbased $\mathrm{S}$ theme has a dampening effect on the overall level of a movement's thematic saturation. Investigating the connection between thematic saturation and expositional plan also provides a window into understanding how Haydn balances thematic returns (density) with the amount of material recycled (quantity).

\section{Acknowledgements}

I would like to thank my research assistants Sabine Gross and Adam Willson for their early contributions to collecting and checking data in the symphonies and for contributing to the analytical style sheet. Funding for their assistance was graciously granted by Oberlin College.

\section{End Notes}

[1] Continuous expositions are included in the corpus. Their thematic plan will always have an " $n$ " in the S column. Sonata rondos are not included in the corpus.

\section{References}

Burstein, P. (2016). Expositional Journeys and Resting Points. Composition as a Problem, 7, 5-16.

Caplin, W. E. (2001). Classical Form: A Theory of Formal Functions for the Instrumental Music of Haydn, Mozart, 
and Beethoven. Oxford University Press.

Duncan, S. P. (2011). Blurring the Boundaries: Toward a Multivalent Reading of Three First-Movement Sonata Forms in Haydn's Op. 50 String Quartets. Musical Explorations, 12, 5-40.

Fillion, M. (2012). Form, rhetoric, and the reception of Haydn's rondo finales. In Engaging Haydn: Culture, Context, and Criticism (pp. 187-210). Cambridge University Press. https://doi.org/10.1017/CBO9781139057714.011

Haimo, E. (1995). Haydn's Symphonic Forms: Essays in Compositional Logic. Oxford University Press.

Hepokoski, J., \& Darcy, W. (2006). Elements of Sonata Theory: Norms, Types, and Deformations in the LateEighteenth-Century Sonata. Oxford University Press. https://doi.org/10.1093/acprof:oso/9780195146400.001. $\underline{0001}$

Korstvedt, B. (2013). On Not Inviting Difficulties in Haydn's Symphonies. Haydn: Online Journal of the Haydn Society of North America, 3(2), 35 pages.

Ludwig, A. (2012). Hepokoski and Darcy's Haydn. HAYDN: Online Journal of the Haydn Society of North America, 2(2), 31 pages.

Miyake, J. (2011). Middles and Muddles: Haydn's Compositional Style and Sonata Forms. In S. E. Murray (Ed.), Haydn and His Contemporaries.

Neuwirth, M. (2011). Joseph Haydn's “witty" play on Hepokoski and Darcy's Elements of Sonata Theory. Zeitschrift Der Gesellschaft Für Musiktheorie [Journal of the German-Speaking Society of Music Theory], 8(1), 199-220. https://doi.org/10.31751/586

Neuwirth, M. (2013). Recomposed Recapitulations in the Sonata-Form Movements of Joseph Haydn and His Contemporaries [Dissertation].

Riley, M. (2015). The Sonata Principle Reformulated for Haydn Post-1770 and a Typology of his Recapitulatory Strategies. Journal of the Royal Musical Association, 140(1), 1-39. https://doi.org/10.1080/02690403.2015.1008862

Rosen, C. (1998). The Classical Style: Haydn, Mozart, Beethoven (Expanded edition). W. W. Norton \& Company.

Tilmouth, M. (2001). Monothematic. Grove Music Online. https://doi.org/10.1093/gmo/9781561592630.article.189 $\underline{83}$ 